\title{
Opioid Prescriptions and Short-Term Mortality: a U.S. National Study
}

\author{
Alicia Agnoli, $\mathrm{MD}, \mathrm{MPH}, \mathrm{MHS}^{7}$, Anthony Jerant, $\mathrm{MD}^{7}$, William Becker, $M D^{2,3}$, and \\ Peter Franks, $M D^{\prime}$
}

'Department of Family and Community Medicine, UC Davis School of Medicine, Sacramento, CA, USA; ${ }^{2}$ Department of Internal Medicine, Yale University School of Medicine, New Haven, CT, USA; ${ }^{3}$ VA Connecticut Healthcare System, West Haven, CT, USA.

BACKGROUND: Opioid-related mortality continues to rise. Though risks of prescription opioid misuse and abuse are well known, short-term mortality across a range of prescription opioid exposure is unclear.

OBJECTIVE: This study was conducted in order to assess the short-term mortality associated with quantity of reported opioid prescriptions,

DESIGN: An observational analysis was performed using data from the Medical Expenditure Panel Survey, years 2005-2015, a population-based, nationally representative household survey.

PARTICIPANTS: This study included adults (age 18+) with prescription data and death status reported during their 2-year survey participation.

MAIN MEASURES: Key exposure is the number of opioid prescriptions $(0,1-5,6$ or more) in year 1 of survey participation. The main outcome is all-cause mortality reported during the 2-year survey participation.

KEY RESULTS: Of 90,622 participants, 14\% reported at least 1 opioid prescription. There were 774 (0.9\%) deaths during the survey period, $551(0.7 \%)$ among those not reporting opioids, 127 (1.2\%) among those reporting $1-5$ opioid prescriptions, and 96 (3.9\%) among those reporting sociodemographics, health status, and utilization, there was no significant association between category of opioid prescriptions and death during the study period; adjusted odds ratios $=0.86(95 \% \mathrm{CI}=0.66,1.22, p=0.27)$ and 0.99 $(95 \% \mathrm{CI}=0.74,1.34, p=0.96)$, respectively, for $1-5$ prescriptions and 6 or more prescriptions.

CONCLUSIONS: In a nationally representative sample, opioid prescriptions were associated with increased short-term mortality only without adjustment for sociodemographics, health status, or utilization. The relationship between prescription opioid use and mortality risk is more complex than previously reported, meriting further examination.

KEY WORDS: opioids; mortality; pain; health status; United States.

DOI: $10.1007 / \mathrm{s} 11606-019-05501-\mathrm{w}$

(c) Society of General Internal Medicine 2019 6 or more opioid prescriptions. After adjusting for

J Gen Intern Med 35(3):656-61

$\mathrm{T}$ he United States (U.S.) faces a growing epidemic of opioid-related mortality ${ }^{1-3}$ which has triggered a wholesale re-examination of the safety of prescription opioid analgesics. The risks of misuse and abuse of prescription opioids are well-known, including overdose and opioid use disorder, ${ }^{4}$ prompting initiatives to reduce initial prescribing and encourage "deprescribing" among patients receiving long-term prescription opioids. ${ }^{5,6}$

In possible contrast to the known mortality risks of misused and nonprescribed opioids, the extent to which receiving prescription opioids is associated with mortality remains understudied. ${ }^{7,8}$ Prior studies of patients with chronic noncancer pain have found long-term or chronic opioid therapy (commonly defined as at least 3 months of continuous use) to be associated with lower health-related quality of life, more disability, more healthcare utilization, and greater risk of opioid use disorder. ${ }^{9} 10$ Some studies similarly indicate a relationship between short-term use of prescription opioids and deleterious outcomes. ${ }^{11-13}$ However, the causal direction of these relationships remains uncertain. Given the growing concerns about prescription opioid safety and possible adverse unintended consequences of restricting and deprescribing opioids (e.g., patient dissatisfaction, worse clinician-patient relationships, and increased illicit drug use),${ }^{14}$ there is an urgent need to better characterize prescription opioid-related mortality risk.

We analyzed data from individuals enrolled for 2 years in the 2005-2015 U.S. Medical Expenditure Panel Survey (MEPS) to examine the relationship between the number of opioid analgesic prescriptions received in participation year 1 and all-cause mortality during survey participation and to explore how patient sociodemographic factors and health status may affect the relationship. Given what is known about the risks associated with opioid misuse, we hypothesized that short-term mortality would be higher among the opioidexposed in the sample.

\section{METHODS}

\section{Data Source}

Revised April 23, 2019

Accepted September 25, 2019

Published online October 30, 2019
MEPS is a nationally representative survey of healthcare use and costs in the U.S. civilian and noninstitutionalized 
population. The survey is conducted by the Agency for Healthcare Research and Quality (AHRQ) as a subset of the National Health Interview Survey and employs an overlapping panel design. Data are collected for individuals over a 2-year period through baseline and follow-up interviews. ${ }^{15}$ The MEPS Household Component collects information on interview language, country of origin, sociodemographic information, usual source of care, and health insurance coverage. Two additional survey components were also examined. The MEPS Prescribed Medicines file is a subcomponent detailing prescription drug information for all survey participants during each of the follow-up interviews. The Medical Conditions file documents all conditions reported by respondents at each follow-up survey. We utilized MEPS data from these three components for the years 2005-2015. Response rates declined from 61.3 to $47.7 \%$ during the study years. ${ }^{16}$

The analytic sample for this study included all participants aged 18 or older who provided baseline data and for whom mortality data was available within their 2-year study participation period. We utilized the overlapping panel design to assess prospectively the association between opioid prescription exposure and other factors (sociodemographic characteristics, markers of health status, and healthcare utilization) in participation year 1 with mortality during survey participation.

\section{Measures}

Opioid Prescriptions. We categorized year 1 prescription opioid exposure using the number of discrete opioid prescriptions reported in the Prescribed Medicines file. Opioid prescriptions were categorized as none (analytic reference), $1-5$, and 6 or more. These categories were chosen to account for incidental, short-term exposure (1-5 prescriptions in the year) and longer-term use (6 or more prescriptions).

Mortality. We assessed short-term all-cause mortality as death occurring during the 2 years of MEPS enrollment. Mortality was counted if death was reported by a household proxy respondent as the person's disposition status in any of the survey rounds.

Covariates. We included key variables to account for sociodemographic characteristics, health status, health behaviors, and healthcare utilization. Sociodemographic covariates included age (in years), sex, self-reported race/ ethnicity (White, Hispanic, Black, Other), U.S. census region (Northeast, Midwest, South, West), education level (less than high school, some high school, high school graduate, some college, college graduate), household income level $(<100$, $100-124,125-199,200-399$, or $\geq 400 \%$ of the federal poverty level), and health insurance status (uninsured, privately insured, or publicly insured). Measures of health status in year 1 included the 12-item Short-Form Health Survey (SF-12), utilizing both the Mental Component Summary (MCS-12) and Physical Component Summary (PCS-12). Separately, we assessed responses to the single question "In general, would you say your health is: excellent, very good, good, fair, or poor?" Both health status measures have been shown to independently predict mortality. ${ }^{16,17}$ We further assessed morbidity using a count of eight self-reported chronic conditions (diabetes, hypertension, coronary heart disease, myocardial infarction, cerebrovascular disease, asthma, emphysema, and arthritis). Separately, persons reporting any visit with a diagnosis of any cancer (excluding only nonmelanoma skin cancer) were coded as having cancer. Self-reported smoking status (nonsmoker vs current smoker) was also assessed. To measure healthcare utilization, a potential marker for morbidity as well as propensity to seek care, we included variables for total year 1 healthcare expenditures and number of physician office visits.

\section{Statistical Analyses}

We analyzed data using Stata version 15.1 in 2017-2018. We utilized longitudinal strata and primary sampling unit identifiers, with survey weights to account for the complex survey design and sampling design of successive waves of the MEPS. We performed a sequence of logistic regression analyses to assess the association between year 1 prescription opioids and death during the study period and to explore how that association varied according to categories of covariates. The key independent variable was opioid prescriptions, assessed as no opioids (reference), 1-5 opioid prescriptions, or 6 or more opioid prescriptions. The initial analysis included no covariates. Next, sociodemographic characteristics (age, sex, race/ethnicity, census region, education level, household income level, and health insurance status) were added as covariates. Next, health status-related covariates were added (mental health status [MCS-12], physical health status [PCS-12], the single question self-rated health), as well as health conditions [count of eight chronic conditions], the presence or absence a cancer diagnosis, and smoking status. Finally, utilization variables (total health expenditures (as the natural $\log$ of [actual expenditures +1 ]) and number of physician office visits) were added. All analyses also adjusted for MEPS panel year to account for potential secular temporal trends. Secular trends were explored further by adding an interaction term between opioid prescription category and time period.

\section{RESULTS}

The analytic sample included 90,622 adult MEPS participants between the years 2005 and 2015 with year 1 baseline and health data and mortality status data.

Table 1 summarizes the characteristics of the analytic sample comparing individuals in each of the opioid prescription categories. In total, $14 \%(n=12,780)$ of the sample reported at least 1 opioid prescription, with the majority of those $(80.6 \%)$ receiving fewer than 6 prescriptions. Only 2480 patients $(2.7 \%$ 
Table 1 Patient Characteristics by Category of Opioid Prescriptions

\begin{tabular}{|c|c|c|c|c|c|}
\hline Characteristic & Total & No opioids & 1-5 prescriptions & $\geq 6$ prescriptions & $\begin{array}{l}p \text { value } \\
\text { (sample) }\end{array}$ \\
\hline$N$ & 90,622 & 77,842 & 10,300 & 2480 & \\
\hline Age, mean (SD) & $45.8(17.4)$ & $45.4(17.5)$ & $47.0(17.2)$ & $55.4(14.5)$ & $<0.001$ \\
\hline Sex, female & $49,377(54.5 \%)$ & $41,354(53.1 \%)$ & $6455(62.7 \%)$ & $1568(63.2 \%)$ & $<0.001$ \\
\hline \multicolumn{6}{|l|}{ Race } \\
\hline White & $43,385(47.9 \%)$ & $36,002(46.3 \%)$ & $5786(56.2 \%)$ & $1597(64.4 \%)$ & \multirow[t]{4}{*}{$<0.001$} \\
\hline Hispanic & $22,642(25.0 \%)$ & $20,638(26.5 \%)$ & $1736(16.9 \%)$ & $268(10.8 \%)$ & \\
\hline Black & $16,873(18.6 \%)$ & $14,171(18.2 \%)$ & $2191(21.3 \%)$ & $511(20.6 \%)$ & \\
\hline Other & $7722(8.5 \%)$ & $7031(9.0 \%)$ & $587(5.7 \%)$ & $104(4.2 \%)$ & \\
\hline \multicolumn{6}{|l|}{ Education } \\
\hline$<$ High school & $8144(9.0 \%)$ & $7189(9.2 \%)$ & $685(6.7 \%)$ & $270(10.9 \%)$ & \multirow[t]{5}{*}{$<0.001$} \\
\hline Some high school & $12,239(13.5 \%)$ & $10,268(13.2 \%)$ & $1489(14.5 \%)$ & $482(19.4 \%)$ & \\
\hline HS graduate & $27,785(30.7 \%)$ & $23,664(30.4 \%)$ & $3250(31.6 \%)$ & $871(35.1 \%)$ & \\
\hline Some college & $21,886(24.2 \%)$ & $18,452(23.7 \%)$ & $2851(27.7 \%)$ & $583(23.5 \%)$ & \\
\hline College graduate & $20,568(22.7 \%)$ & $18,269(23.5 \%)$ & $2025(19.7 \%)$ & $274(11.0 \%)$ & \\
\hline \multicolumn{6}{|c|}{ Household income, \% federal poverty level } \\
\hline$<100$ & $16,277(18.0 \%)$ & $13,368(17.2 \%)$ & $2131(20.7 \%)$ & $778(31.4 \%)$ & \multirow[t]{5}{*}{$<0.001$} \\
\hline$<125$ & $5480(6.0 \%)$ & $4626(5.9 \%)$ & $616(6.0 \%)$ & $238(9.6 \%)$ & \\
\hline$<200$ & $15,043(16.6 \%)$ & $12,950(16.6 \%)$ & $1626(15.8 \%)$ & $467(18.8 \%)$ & \\
\hline$<400$ & $27,128(29.9 \%)$ & $23,507(30.2 \%)$ & $3021(29.3 \%)$ & $600(24.2 \%)$ & \\
\hline $400+$ & $26,694(29.5 \%)$ & $23,391(30.0 \%)$ & $2906(28.2 \%)$ & $397(16.0 \%)$ & \\
\hline \multicolumn{6}{|l|}{ Census region } \\
\hline Northeast & $13,870(15.3 \%)$ & $12,312(15.8 \%)$ & $1269(12.3 \%)$ & $289(11.7 \%)$ & \multirow[t]{4}{*}{$<0.001$} \\
\hline Midwest & $18,008(19.9 \%)$ & $15,062(19.3 \%)$ & $2361(22.9 \%)$ & $585(23.6 \%)$ & \\
\hline South & $34,518(38.1 \%)$ & $29,284(37.6 \%)$ & $4133(40.1 \%)$ & $1101(44.4 \%)$ & \\
\hline West & $24,226(26.7 \%)$ & $21,184(27.2 \%)$ & $2537(24.6 \%)$ & $505(20.4 \%)$ & \\
\hline \multicolumn{6}{|l|}{ Insurance status } \\
\hline Private & $53,440(59.0 \%)$ & $46,125(59.3 \%)$ & $6342(61.6 \%)$ & $973(39.2 \%)$ & \multirow[t]{3}{*}{$<0.001$} \\
\hline Public & $19,603(21.6 \%)$ & $15,469(19.9 \%)$ & $2815(27.3 \%)$ & $1319(53.2 \%)$ & \\
\hline None & $17,579(19.4 \%)$ & $16,248(20.9 \%)$ & $1143(11.1 \%)$ & $188(7.6 \%)$ & \\
\hline \multicolumn{6}{|c|}{ 12-Item Short Form Health Survey component, mean (SD) } \\
\hline PCS & $49.0(10.8)$ & $50.2(9.8)$ & $44.4(12.3)$ & $30.1(11.1)$ & $<0.001$ \\
\hline MCS & $50.6(10.2)$ & $51.1(9.8)$ & $48.6(11.2)$ & $42.0(12.7)$ & $<0.001$ \\
\hline \multicolumn{6}{|l|}{ Self-rated health } \\
\hline Excellent & $20,565(22.7 \%)$ & $19,055(24.5 \%)$ & $1449(14.1 \%)$ & $61(2.5 \%)$ & \multirow[t]{5}{*}{$<0.001$} \\
\hline Very good & $28,889(31.9 \%)$ & $25,812(33.2 \%)$ & $2818(27.4 \%)$ & $259(10.4 \%)$ & \\
\hline Good & $26,718(29.5 \%)$ & $22,683(29.1 \%)$ & $3441(33.4 \%)$ & $594(24.0 \%)$ & \\
\hline Fair & $11,129(12.3 \%)$ & $8387(10.8 \%)$ & $1888(18.3 \%)$ & $854(34.4 \%)$ & \\
\hline Poor & $3321(3.7 \%)$ & $1905(2.4 \%)$ & $704(6.8 \%)$ & $712(28.7 \%)$ & \\
\hline Current smoker & $16,620(18.3 \%)$ & $13,251(17.0 \%)$ & $2432(23.6 \%)$ & $937(37.8 \%)$ & $<0.001$ \\
\hline $\begin{array}{l}\text { Count of chronic diseases, median } \\
\text { (IQR) }\end{array}$ & $0.00(0.00,1.00)$ & $0.00(0.00,1.00)$ & $1.00(0.00,2.00)$ & $2.00(1.00,3.00)$ & $<0.001$ \\
\hline Count of chronic diseases, mean (SD) & $0.89(1.21)$ & $0.80(1.14)$ & $1.24(1.36)$ & $2.36(1.53)$ & $<0.001$ \\
\hline Any cancer diagnosis & $3164(3.5 \%)$ & $2258(2.9 \%)$ & $645(6.3 \%)$ & $261(10.5 \%)$ & $<0.001$ \\
\hline $\begin{array}{l}\text { Year } 1 \text { total healthcare expenditures, } \\
\text { median (IQR) }\end{array}$ & $\begin{array}{l}983.0(136.0, \\
3853.0)\end{array}$ & $\begin{array}{l}703.0(79.0 \\
2779.0)\end{array}$ & $\begin{array}{l}4566.0(1564.5 \\
11,379.0)\end{array}$ & $\begin{array}{l}9473.0(4255.5 \\
20,688.0)\end{array}$ & $<0.001$ \\
\hline Office visits, median (IQR) & $1.0(0.0,4.0)$ & $1.0(0.0,3.0)$ & $4.0(1.0,8.5)$ & $8.0(4.0,15.0)$ & $<0.001$ \\
\hline \multicolumn{6}{|l|}{ Opioid prescriptions, year 1} \\
\hline None & $77.842(85.9 \%)$ & $77,842(100.0 \%)$ & - & - & \multirow[t]{3}{*}{$<0.001$} \\
\hline $1-5$ & $10,300(11.4 \%)$ & - & $10,300(100.0 \%)$ & - & \\
\hline$\geq 6$ & $2480(2.7 \%)$ & - & - & $2480(100.0 \%)$ & \\
\hline Died during survey period & $774(0.9 \%)$ & $551(0.7 \%)$ & $127(1.2 \%)$ & $96(3.9 \%)$ & $<0.001$ \\
\hline
\end{tabular}

Table 1 data are sample-based and have not been adjusted for survey characteristics. $p$ values are based on the sample and are not survey-adjusted $S D=$ standard deviation, $I Q R=$ interquartile range, $P C S=$ Physical Component Summary of Short-Form Health Survey, MCS = Mental Component Summary of Short-Form Health Survey

of the total sample) reported 6 or more opioid prescriptions. Patients receiving opioids were more likely to be older, female, White, and of lower income; to live in the Midwest or South census regions; and to be publicly insured. They were also more likely to have poor health status, with lower average PCS and MCS scores, lower self-rated health, and higher rates of smoking and cancer diagnoses. Persons reporting more opioid prescriptions were also more likely to die during their 2-year MEPS participation period (Table 1): Among individuals reporting 6 or more opioid prescriptions, $3.9 \%$ died during the survey period, compared to $1.2 \%$ of the category reporting $1-5$ opioid prescriptions and $0.9 \%$ of those reporting no opioids.
In Table 2, the results of sequential regression models are shown that examined how the unadjusted association between prescription opioids and short-term mortality was affected by adjusting for different categories of covariates. Model 1, the unadjusted model, yielded an odds ratio of mortality of 1.53 $(95 \% \mathrm{CI}=1.20-1.94, p<0.01)$ for the $1-5$ opioid prescription category and an odds ratio of $5.48(95 \% \mathrm{CI}=4.23-7.11, p<$ 0.01 ) for the category of 6 or more opioid prescriptions, both as compared to the statistical reference of no opioids. In model 2 , which included adjustment for key sociodemographic variables (age, sex, race, education level, household income, census region, and insurance status), the odds ratio for the 15 opioid prescription category remained essentially unchanged 
Table 2 Unadjusted and Adjusted Odds of Mortality by Opioid Prescription Category (with 95\% Confidence Intervals)

\begin{tabular}{|c|c|c|c|c|}
\hline Logistic regression model & 1-5 prescriptions & $p$ value & $\geq 6$ prescriptions & $p$ value \\
\hline 1. Unadjusted & $1.53(1.20,1.94)$ & 0.001 & $5.48(4.23,7.11)$ & $<0.001$ \\
\hline 2. Sociodemographics & $1.51(1.18,1.92)$ & 0.001 & $3.20(2.39,4.29)$ & $<0.001$ \\
\hline 3. Sociodemographics + Health status related & $0.99(0.77,1.29)$ & 0.965 & $1.14(0.85,1.53)$ & 0.395 \\
\hline 4. Sociodemographics, health status related + utilization & $0.86(0.66,1.12)$ & 0.269 & $0.99(0.74,1.34)$ & 0.963 \\
\hline
\end{tabular}

Reference group for all odds ratios: no opioid prescriptions. Model 1 is unadjusted. Model 2 adjusted for sociodemographic variables: age, sex, race, education level, household income, census region, and insurance status. Model 3 included all covariates in model 2 plus additional markers of health status: SF-12 Physical and Mental components (PCS, MCS), self-rated health, count of eight key comorbidities, cancer diagnosis, and smoking status. Model 4 included all covariates in model 3 plus additional markers of healthcare utilization: total year 1 healthcare expenditures (log[expenditures + 1]) and number of doctor's office visits

(adjusted odds ratio $(\mathrm{aOR})=1.51,95 \% \mathrm{CI}=1.18-1.92, p<$ $0.01)$. The aOR for 6 or more opioid prescriptions decreased to $3.20(95 \% \mathrm{CI}=2.39-4.92, p<0.01)$. In model 3 , which added additional adjustment for health status, the odds ratios were no longer significant: for 1-5 opioid prescriptions, mortality aOR $=0.99(95 \% \mathrm{CI}=0.77-1.29, p=0.96)$, and for 6 or more

Table 3 Adjusted Odds of Short-Term Mortality by Patient Characteristics

\begin{tabular}{|c|c|c|}
\hline Factor & $\begin{array}{l}\text { Adjusted odds } \\
\text { of death }\end{array}$ & $\overline{p \text { value }}$ \\
\hline \multicolumn{3}{|l|}{ Opioid category $($ ref $=$ none $)$} \\
\hline $1-5$ opioid prescriptions & $0.86(0.66,1.12)$ & 0.269 \\
\hline$\geq 6$ opioid prescriptions & $0.99(0.74,1.34)$ & 0.963 \\
\hline Age & $1.07(1.06,1.08)$ & 0.000 \\
\hline Sex, female & $0.57(0.48,0.67)$ & 0.000 \\
\hline \multicolumn{3}{|l|}{ Race (ref = White) } \\
\hline Hispanic & $0.67(0.50,0.90)$ & 0.009 \\
\hline Black & $1.35(1.09,1.67)$ & 0.006 \\
\hline Other & $0.96(0.67,1.38)$ & 0.843 \\
\hline \multicolumn{3}{|c|}{ Education (ref $=$ less than high school) } \\
\hline Some high school & $1.35(0.99,1.84)$ & 0.058 \\
\hline High school graduate & $1.15(0.88,1.49)$ & 0.301 \\
\hline Some college & $0.93(0.68,1.28)$ & 0.674 \\
\hline College graduate & $0.81(0.57,1.16)$ & 0.248 \\
\hline \multicolumn{3}{|c|}{ Household income (ref $=<100 \%$ FPL) } \\
\hline $100-124 \%$ FPL & $1.14(0.82,1.57)$ & 0.444 \\
\hline $125-199 \%$ FPL & $0.97(0.74,1.26)$ & 0.805 \\
\hline $200-399 \% \mathrm{FPL}$ & $1.05(0.80,1.39)$ & 0.710 \\
\hline $400 \%+\mathrm{FPL}$ & $0.75(0.53,1.08)$ & 0.118 \\
\hline \multicolumn{3}{|l|}{ Census region (ref $=$ Northeast) } \\
\hline Midwest & $1.07(0.80,1.42)$ & 0.645 \\
\hline South & $0.96(0.75,1.24)$ & 0.762 \\
\hline West & $0.95(0.71,1.28)$ & 0.745 \\
\hline \multicolumn{3}{|l|}{ Insurance status $($ ref $=$ private $)$} \\
\hline Public & $1.20(0.98,1.48)$ & 0.075 \\
\hline None & $1.55(1.10,2.17)$ & 0.012 \\
\hline Panel & $1.02(0.99,1.04)$ & 0.236 \\
\hline \multicolumn{3}{|c|}{ 12-Item Short Form Health Survey component } \\
\hline Physical component score & $0.96(0.95,0.97)$ & 0.000 \\
\hline Mental component score & $0.98(0.97,0.99)$ & 0.000 \\
\hline \multicolumn{3}{|l|}{ Self-rated health (ref = excellent) } \\
\hline Very good & $1.27(0.84,1.93)$ & 0.259 \\
\hline Good & $1.00(0.65,1.53)$ & 0.982 \\
\hline Fair & $1.48(0.93,2.35)$ & 0.095 \\
\hline Poor & $3.47(2.07,5.80)$ & 0.000 \\
\hline Current smoker & $1.51(1.18,1.94)$ & 0.001 \\
\hline Count of chronic diseases & $0.96(0.89,1.03)$ & 0.208 \\
\hline Any cancer diagnosis & $2.70(2.20,3.31)$ & 0.000 \\
\hline Year 1 total healthcare expenditures & $1.13(1.03,1.24)$ & 0.007 \\
\hline Office visits & $0.99(0.98,1.01)$ & 0.435 \\
\hline
\end{tabular}

Table 3 data have also been adjusted for survey characteristics and panel year

Ref $=$ reference category, $F P L=$ federal poverty level, $P C S=$ Physical Component Summary of Short-Form Health Survey, MCS = Mental Component Summary of Short-Form Health Survey, Year 1 total healthcare expenditures $=\log [$ expenditures +1$]$ opioids, $\mathrm{aOR}=1.14(95 \% \mathrm{CI}=0.85-1.53, p=0.40)$. The final model (model 4 ) added adjustment for healthcare utilization (total healthcare expenditures and doctor's office visits) and also demonstrated no statistical difference in mortality risk between the categories of opioid prescriptions and those prescribed no opioids.

The analysis including an interaction term between opioid prescription category and time period did not demonstrate a significant interaction $(F(10,436)=0.78, p=0.65)$.

Table 3 shows the results of the final regression analysis assessing this relationship between opioid category and shortterm mortality after adjustment for all key covariates. In the final model, as compared to the reference category of no opioids, the aOR for death in the $1-5$ opioid prescription category was $0.86(95 \% \mathrm{CI}=0.66-1.12, p=0.27)$, and the aOR in the 6 or more category was $0.99(95 \% \mathrm{CI}=0.74-1.34$, $p=0.96)$. The most significant predictors of short-term mortality in the fully adjusted model included higher age, male sex, Black race, no insurance, smoking, cancer, and higher total health expenditures.

\section{DISCUSSION}

In a nationally representative U.S. sample of individuals enrolled in the MEPS for two consecutive years, we found that receipt of opioid prescriptions in participation year 1 was not associated with increased risk of death during the 2-year survey period, after adjusting for sociodemographic factors, health status, and healthcare utilization. This was true both for participants receiving incident and/or short-term prescriptions as well as those receiving longer-term prescriptions. Unadjusted analysis, as well as the sociodemographically adjusted analysis, revealed an increased mortality risk associated with both categories of opioid prescriptions. That increased risk was eliminated with further adjustment for health status. Finally, additional adjustment for healthcare utilization produced no further significant change in the opioid mortality association.

Though opioid overdose mortality in the U.S. has increased notably over the past 15 years, likely due to misuse of opioids and transition to heroin (and, more recently, fentanyl and other synthetic analogs), the impact of prescribed opioids on allcause mortality has received less attention. ${ }^{18}$ Our findings 
indicated no increase in short-term mortality associated with receiving prescription opioids after adjustment for health status, even among the patients who likely received them for longer-term therapy.

Our study found there were substantial sociodemographic and health differences between individuals reporting and those not reporting prescribed opioids. Those prescribed opioids were, on average, older, more likely women, poorer, and less healthy than others. These findings are consistent with previous surveillance studies. ${ }^{19,20}$ The combination of sociodemographic and health status differences likely explains the opioid prescription-mortality association we observed in the unadjusted analysis.

The attenuation of the unadjusted mortality association with opioid prescribing occurred primarily after adjusting for health status. There are at least two potential explanations for this observation. It may be that receiving opioids leads one to be in poorer health (as measured, for example, by lower self-rated health). If this were so, then there may be an increased mortality risk among patients receiving opioid prescriptions that is effectively "masked" in our adjusted model; in other words, the model is overadjusted. Alternatively, receipt of prescription opioids may be a consequence of patient factors (especially poorer health status) that confer increased mortality risk. While the observational nature of our analyses precludes drawing causal inferences, future appropriately designed studies to examine these hypotheses would be useful.

One potential conclusion to draw from these results is that most patients who are prescribed opioids use them as prescribed and do not experience the risks known to be associated with opioid misuse or use of illicit opioids. This is an important distinction considering the sweeping policies and practice changes aimed at restricting opioid prescribing; however, evidence suggests the current opioid epidemic is driven by illicit and synthetically derived opioids. ${ }^{2}$ Our findings suggest a need for greater attention to individual risks for opioidrelated adversity, balanced against the necessary objectives of safely and effectively managing pain.

The strengths of our study included the use of a nationally representative sample and the examination of the associations with different categories of prescription use. The existing literature has often conflated opioid abuse and misuse with all use of opioids. Additionally, examining short-term mortality is important. Though we are unable to assess any longerterm association between opioid prescriptions and mortality, the short-term outcome allowed us to assess a more direct link between the exposure and the outcome with less opportunity for exogenous events to confound the relationship during follow-up.

Our study also has certain limitations. Though prior work has shown associations between prescription opioids and other outcomes including nonfatal overdose and dependence, we were unable to examine these potential harms in our analysis. ${ }^{21-23}$ Secondly, nonresponse to the MEPS may also have introduced bias, as it is unknown whether opioid-related risk behaviors differ among responders and nonresponders. We also acknowledge that, though designed to be nationally representative of the general household U.S. population, MEPS excludes certain populations that may be at higher risk for opioid misuse and related mortality, such as hospitalized and institutionalized persons. Our study also lacked information regarding the doses (e.g., morphine-equivalent units) of prescribed opioids. Many prior studies have demonstrated greater risks associated with higher prescription opioid doses. Nonetheless, examining the risk associated with duration of receipt of prescription opioids, independent of dosage, is still worthwhile given studies suggesting greater harms resulting from greater duration of use. ${ }^{24}$ Finally, it is possible that continuous opioid exposure is associated with greater risk of harm, but there were relatively few respondents with higher quantities (e.g., 12 or more) of opioid prescriptions reported in year 1 of their MEPS participation to be able to meaningfully subanalyze this group.

In conclusion, this analysis found that individuals reporting opioid prescriptions had no greater short-term mortality than those reporting no exposure to opioids after sociodemographic and health status adjustment. These findings highlight the need for further work to understand the risk of opioid analgesic prescriptions in the general population. As these risks are likely highly variable, future efforts should attempt to better clarify individual risk predictors of morbidity and mortality among patients prescribed opioids for pain.

Corresponding Author: Alicia Agnoli, MD, MPH, MHS; Department of Family and Community Medicine UC Davis School of Medicine, Sacramento, CA, USA (e-mail: aagnoli@ucdavis.edu).

Funding Information Dr. Agnoli's work on this project was partially supported by the Dean's Scholar in Women's Health Research (DSWHR) career development award, funded by the UC Davis School of Medicine Dean's Office. The funding source had no role in the study design, handling of data, or decisions regarding the manuscript.

\section{Compliance with Ethical Standards:}

Conflict of Interest: The authors declare that they do not have a conflict of interest.

\section{REFERENCES}

1. Rudd RA, Aleshire N, Zibbell JE, Gladden RM. Increases in drug and opioid overdose deaths-United States, 2000-2014. MMWR. 2016, 64(50); 1378-82.

2. CDC. Understanding the epidemic: drug overdose deaths continue to increase in the United States. Accessed at http://www.cdc.gov/ drugoverdose/epidemic/index.html on August 29, 2019.

3. Berterame S, Erthal $\mathbf{J}$, Thomas $\mathbf{J}$, et al. Use of and barriers to access to opioid analgesics: a worldwide, regional, and national study. Lancet. 2016;387:1644-56. https://doi.org/10.1016/S0140-6736(16)00161-6.

4. Chou R, Turner JA, Devine EB, et al. The effectiveness and risks of long-term opioid therapy for chronic pain: a systematic review for a National Institutes of Health Pathways to Prevention Workshop. Ann Intern Med. 2015;162:276-86.

5. Dowell D, Haegerich TM, Chou R. CDC guideline for prescribing opioids for chronic pain-United States, 2016. JAMA. 2016;315:1624-45. 
6. Department of Veterans Affairs; Department of Defense; Opioid Therapy for Chronic Pain Work Group. VA/DoD Clinical Practice Guideline for Opioid Therapy for Chronic Pain. Version 3.0. Washington, DC: U.S. Department of Veterans Affairs; 2017. Accessed at www.healthquality.va. gov/guidelines/Pain/cot on August 29, 2019.

7. Nechuta SJ, Tyndall BD, Mukhopadhyay S, McPheeters ML. Sociodemographic factors, prescription history and opioid overdose deaths: a statewide analysis using linked PDMP and mortality data. Drug Alcohol Depend. 2018;190:62-71.

8. Weisberg DF, Gordon KS, Barry DT, et al. Long-term prescription opioids and/or benzodiazepines and mortality among HIV-infected and uninfected patients. J Acquir Immune Defic Syndr. 2015;69(2):223.

9. Sites BD, Beach ML, Davis MA. Increases in the use of prescription opioid analgesics and the lack of improvement in disability metrics among users. Reg Anesth Pain Med. 2014;39(1):6-12.

10. Ashworth J, Green DJ, Dunn KM, Jordan KP. Opioid use among low back pain patients in primary care: is opioid prescription associated with disability at 6-month follow-up? Pain. 2013;154(7):1038-44.

11. Edlund MJ, Martin BC, Russo JE, DeVries A, Braden JB, Sullivan MD. The role of opioid prescription in incident opioid abuse and dependence among individuals with chronic noncancer pain: the role of opioid prescription. Clin J Pain. 2014;30(7):557-64.

12. Shah A, Hayes CJ, Martin BC. Characteristics of initial prescription episodes and likelihood of long-term opioid use-United States, 20062015. MMWR Morb Mortal Wkly Rep. 2017;66:265-269.

13. Jeffery MM, Hooten WM, Henk HJ, et al. Trends in opioid use in commercially insured and Medicare Advantage populations in 2007-16: retrospective cohort study. BMJ. 2018; 362

14. Frank JW, Lovejoy TI, Becker WC, et al. Patient outcomes in dose reduction or discontinuation of long-term opioid therapy: a systematic review. Ann Intern Med 2017;167:181-191. https://doi.org/10.7326/ M17-0598.

15. Medical Expenditure Panel Survey (MEPS). Agency for Healthcare Research and Quality, Rockville, MD. Accessed at https://meps.ahrq gov/mepsweb/ on August 29, 2019
16. Medical Expenditure Panel Survey (MEPS). Agency for Healthcare Research and Quality, Rockville, MD. Accessed at https://meps.ahrq gov/survey_comp/hc_response_rate.jsp on August 29, 2019.

17. DeSalvo KB, Bloser N, Reynolds K, He J, Muntner P. Mortality prediction with a single general self-rated health question. A metaanalysis. J Gen Intern Med. 2006; 21(3):267-75.

18. Gomes T, Khuu W, Martins D, et al. Contributions of prescribed and non-prescribed opioids to opioid related deaths: population based cohort study in Ontario, Canada. BMJ. 2018;362:362.

19. Qureshi ZP, Haider MR, Rodriguez-Monguio R, et al. Opioid prescription drug use and expenditures in US outpatient physician offices: evidence from two nationally representative surveys. Cancer Ther Oncol Int J. 2017;3(3).

20. Serdarevic M, Striley CW, Cottler LB. Sex differences in prescription opioid use. Curr Opin Psychiatry. 2017;30(4):238-46.

21. Bohnert ASB, Valenstein M, Bair MJ, et al. Association between opioid prescribing patterns and opioid overdose-related deaths. JAMA. 2011;305(13):1315-1321. https://doi.org/10.1001/jama.2011.370.

22. Dunn KM, Saunders KW, Rutter CM, et al. Opioid prescriptions for chronic pain and overdose: a cohort study. Ann Intern Med. 2010;152:85-92. https://doi.org/10.7326/0003-4819-152-2201001190-00006.

23. Clarke H, Soneji N, Ko DT, Yun L, Wijeysundera DN. Rates and risk factors for prolonged opioid use after major surgery: population based cohort study. BMJ. 2014; 348. https://doi.org/10.1136/bmj.g1251.

24. Brat GA, et al. Postsurgical prescriptions for opioid naive patients and association with overdose and misuse: retrospective cohort study. BMJ. 2018; 360. https://doi.org/10.1136/bmj.j5790.

Publisher's Note Springer Nature remains neutral with regard to jurisdictional claims in published maps and institutional affiliations. 